\title{
IMPLEMENTATION OF THE EU NOISE DIRECTIVE IN PROCESS OF URBAN PLANNING IN POLAND
}

\author{
J. Kwiecień ${ }^{\text {a, } *, \text { K. Szopińska }}{ }^{\text {a }}$
}

${ }^{a}$ Dept. of Geomatics, Geodesy and Spatial Economy, University of Technology and Life Sciences, Bydgoszcz, Poland jkw@utp.edu.pl

KEY WORDS: Urban planning, Environmental noise, Acoustic climate, Strategic Noise Map, Poland

\begin{abstract}
:
In Poland spatial planning policies are described by a system of planning documents controlled by act of Spatial Planning and Land Development of 27 March 2003. Sustainable development principle and spatial order form is the basis of spatial planning efforts. In the territory of Poland the manner of urban space management is defined by a planning document called Local Land Use Plan (LLUP). In a LLUP some issues are arranged, such as the purpose of a given area, location of public purpose investments, land development conditions. When analysing the development process of Polish cities, an obvious conclusion emerges about the lack of complex studies and researches of the environment concerning the issue of acoustic climate. The procedures of development of an LLUP involve merely a general diagnosis of an environment excluding measured values of pollution, including noise levels.

The main aim of this article is to introduce the influence of acoustic climate on the urban space planning in Poland through the implementation of the provisions of Directive 2002/49/WE of the European Parliament and the Council of Europe from 25 June 2002. Moreover, in the stages of an LLUP implementations have been suggested the use of a Strategic Noise Map, being a tool for assisting the process of environmental noise level assessment in Poland.
\end{abstract}

\section{INTRODUCTION}

Spatial planning is a continuous process of adapting the components to each other and seeking to restore the optimum in case of abnormal operation of developmental factors. Planning is the first step toward the formation of such a state of the natural environment for its functions resulted from the human needs, taking into account the principles of ecological development (Xie et al., 2011). The main problem is to reconcile the demands of modern civilization, maintaining unchanged the natural environment. Noise is one of the main factors degrading the environment and is often found in urban areas (Yu and Kang, 2011). With the rapid development of cities and decreasing of urban space and increasing number of emitters of noise, the problem of its impact on oversize level has become a common phenomenon (Arana et al., 2010). Noise in urban areas causes discomfort among the population and affects negatively the management of resources (Kwiecien et al., 2010). Maintaining the acoustic climate at the appropriate level will allow the full potential of urban space while maintaining environmental values in accordance with the principles of sustainable development and spatial order.

As for communal local legal regulations being the support for urban development, it is the Local Land Use Plan (LLUP) (Szopińska, 2011). In actions related to urban space planning, and especially while identifying noise-sensitive areas, assessment of noise levels of sources included in an LLUP is essential for proper functioning and organization of a city. Currently in Poland the issue of environmental noise and methods of protection against it is not sufficiently identified in the process of preparation of LLUP. Preliminary research results confirmed the necessity of including noise level influence in the procedures related to urban space planning especially concerning its forecasted levels resulting from estimates of LLUP (Szopińska et al., 2012).

\section{DISCUSSION OF POLISH REGULATIONS RELATING TO URBAN SPACE PLANNING SYSTEM IN POLAND}

The main legal act regulating the issues of spatial planning in Poland is Spatial Planning and Land Development Act of 27 March 2003. The basis for planning activities, as defined above, are the principles of sustainable development and spatial order. The tasks of spatial policy in Poland defines the system planning studies carried out at different levels of the administrative division of the country by decisions at the national level, regional level, county level and commune level. At the national level is formed the National Spatial Development Concept, at the regional level the Regional Land Use Plan, and land use at the commune level is realized through: Commune Development Strategy, Study of Land-Use Conditions and Directions and Local Land Use Plan (LLUP). The structure of spatial planning in Poland is the vertical relationship, which corresponds to rule ,from the general to the particular". Equally important is the horizontal co-operation between individuals at the same level of authorities. This is particularly important in the implementation of planning responsibilities at the commune level (local scheduling), where the spatial implement policy objectives set several planning studies.

As for communal local legal regulations being the support for urban development, it is the LLUP. In a LLUP the area designation, the distribution of a public investment and the development and zoning of land is determined. The authors propose to determine land use in such a way as to be consistent

\footnotetext{
* Corresponding author.
} 
with the economic needs of different fields, was known and predictable and socially acceptable to the principles of sustainable development. Stages of the LLUP has been presented in Figure 1 (at the moment the process of creating LLUP does not include findings from the strategic noise maps bold text in Figure 1). LLUP as an act of local law, which plays a major role in forming urban space and on the power of his findings we can be obtained administrative decision - building permit. Local Land Use Plans are implemented within territorially administrative municipalities, and so not all municipal areas have enacted legal enactments. In Poland, only $25.6 \%$ of the country has existing a LLUP. In addition, between the provinces there is a large variation in the percentage of land, for which it is adopted Local Land Use Plan, more than $60 \%$ to only a few percent.

\section{DISCUSSION OF EU LEGISLATION AND POLISH LEGISLATION RELATING TO POLICY OF NOISE}

The problem of noise reflected in the Directive 2002/49/WE of the European Parliament and the Council of Europe from June 25, 2005 which concerned assessing and management of noise levels in an environment. It is an obligation of all the member states of EU to determine noise levels and indicate policies to enhance acoustic conditions as well as protection of areas of acceptable noise levels. Poland, as a member of EU is obliged to comply with the regulations of the previously mentioned
Directive. In Polish legal system he most fundamental legislative act regulating the issues of environmental noise is Environment Protection Law Act of April 272001 as amended. According to article 112 noise exposure protection means providing the most accurate condition of acoustic climate by maintaining the level of noise which does not exceed admissible values.

One of the actions aiming at protection against noise suggested by the directive is the Strategic Noise Map (SNM). SNM is an averaged map of noise generated into environments by various groups of sources. It enables holistic evaluation of a level of noise exposure within an urban area, provides the possibility to determine the origins of such phenomena as well as the opportunity to prepare general prognoses of alterations of its levels (Krajewska and Szopińska, 2012). In the process of preparation of an SNM, environmental noise may be denoted by $\mathrm{L}_{\text {den }}$ and $\mathrm{L}_{\text {night }}$ indicators. $\mathrm{L}_{\mathrm{den}}-$ is a long-term noise indicator, estimated within 24-hour cycles of a year, considering daytime, evening and night time. $\mathrm{L}_{\text {night }}$ - is a long-term noise indicator, estimated during night hours. Their acceptable values in affected areas are estimated in the Directive of Ministry of Environment of October 1, 2012 Amending Regulation on Acceptable Noise Levels in the Environment. The value of indicators is related to the origin of sound source and the purpose of a location affected (Tab. 1).

\begin{tabular}{|l|c|c|c|c|}
\hline \multirow{2}{*}{ Area type } & \multicolumn{4}{|c|}{ Acceptable noise level (dB) } \\
\cline { 2 - 5 } & \multicolumn{2}{|c|}{ Roads or railway } & \multicolumn{2}{|c|}{$\begin{array}{c}\text { Other facilities and activities } \\
\text { being the noise sources }\end{array}$} \\
\cline { 2 - 5 } & $\mathrm{L}_{\mathrm{den}}$ & $\mathrm{L}_{\text {night }}$ & $\mathrm{L}_{\mathrm{den}}$ & \multicolumn{2}{|c|}{40} \\
\hline $\begin{array}{l}\text { Protected zone "A" - spas, areas of hospitals located outside } \\
\text { cities }\end{array}$ & 50 & 45 & 45 & 40 \\
\hline $\begin{array}{l}\text { Areas of single family dwellings, nursing homes and } \\
\text { hospitals in cities as well as residential areas for permanent } \\
\text { and temporary inhabitants. }\end{array}$ & 64 & 59 & 50 & 45 \\
\hline $\begin{array}{l}\text { Areas of multi-family residential units, homestead housing, } \\
\text { recreational areas, housing and service oriented areas }\end{array}$ & 68 & 59 & 55 & 45 \\
\hline $\begin{array}{l}\text { City center zones of cities with the population exceeding } \\
100000 \text { inhabitants }\end{array}$ & 70 & 65 & 55 & 45 \\
\hline
\end{tabular}

Table 1. Acceptable noise level for particular groups of sources

According to the Directive of Ministry of Environment of October 1, 2007 on Data Range Included, Located and Presented in Noise Maps, an SNM consists of a descriptive and graphical part. The first one includes characteristics of an area, acoustic features included in planning documentation of a commune, identification and specification of noise sources as well as identification of endangered areas. The graphical part is represented by numerous maps depicting acoustic climate of a researched area which may include: immision maps, conflict noise maps as well as level indicators of inhabitants excessive noise exposure. Additionally the map includes quiet areas where excessive sound levels have been identified with $L_{\text {den }}$ indicator. As a result, certain actions are then imposed on the area to at least maintain the values which have been received. Noise map calculations are made on the basis of the database received from the Geographic Information Systems and with the use of expert computer software such as CadnaA, SoundPlan, Mithra, ArcAkus or IMMI (Asensio et al., 2009, Fyhri and Aasvang, 2010, Souza and Giunta, 2011, Szopińska et al., 2012).
GIS as the main environment for spatial data management is used in the analysis of an environmental noise. GIS database used for acoustic analysis consists of two independent components, ie.: the descriptive information on the state of urban space with the characteristics of the noise sources and digital maps. The final step in creating a strategic noise map is the implementation of geospatial data to the computer software involved in the calculation of the acoustic climate. GIS data for noise map can come from a variety sources such as:

- road networks, buildings, industrial plants, airports, terrain;

- data collected by the recording equipment in the field (electronic sensors, cameras) such as devices for measuring environmental noise, traffic;

- data collected directly by the people, for example, field sketches, questionnaires, surveys;

- graphical data on the location of surface noise sources and noise sensitive areas;

- processed data in digital or analog form, such as maps, statistical data; 
Article 7 of the Directive 2002/49/WE imposes the obligation to make SNM showing the situation in the preceding calendar year for agglomerations within their territories no later than -30 June 2007 - for agglomerations exceeding 250000 inhabitants and 30 June 2012 - for all agglomerations. In the directive context the term "agglomeration" means part of a territory having a population in excess of 100000 and population density allowing a Member State to consider it an urbanized area. According to the Directive 2002/49/WE and polish law regulations Strategic Noise Maps have been prepared for all the Polish cities exceeding 250,000 and 100,000 inhabitants.

\section{STAGES OF LOCAL USE PLAN INCLUDING THE STRATEGIC NOISE MAP}

According to Article 71 of Environment Protection Law Act of 27 April 2001 along with its further changes, environmental protection issues form the basis a Local Land Use Plan. In accordance with the act, local plans must include all the necessary solutions preventing pollution and give directions for planning to take into consideration the aspect of maintaining ecological balance and to rationally manage natural resources in relation to the need of protection from noise exposure. The requirements are fulfilled in various manners in local planning:

- Defining areas of limited or restricted use including quiet areas of acceptable noise levels. Identifying areas of different functions and land development conditions such as noise-sensitive areas with existing acoustic standards of environmental quality;

- Such protected areas include: areas for residential buildup, noise-sensitive buildings such as hospitals, nursery homes, areas for spas and for buildings of permanent or temporary residence for children and minors;

- Locating areas of manufacturing, warehousing or storing activities in distances which eliminate their negative influence on the environment and people. The influence is characterized by excessive levels of industrial noise.

The Local Land Use Plan preparation procedure includes verification of existing conditions as well as identification of changes in spatial organization. The preparation stages were divided into four major phases by Cymerman (Cymerman, 2010) (Fig. 1). Phase 0 is characterized by collecting initial input data providing information about the area. Such resources include a master map, ecophysiography as well as urban planning inventory. The needed analysis of natural environment condition is provided by ecophysiography. Such a study includes information about current condition along with possible threats to individual environmental components including noise levels and its possible value alterations in relation to time. After assessment and verification of completion of collected initial data, phase 1 follows - analytic work.

GATHERING MATERIAL INPUTS

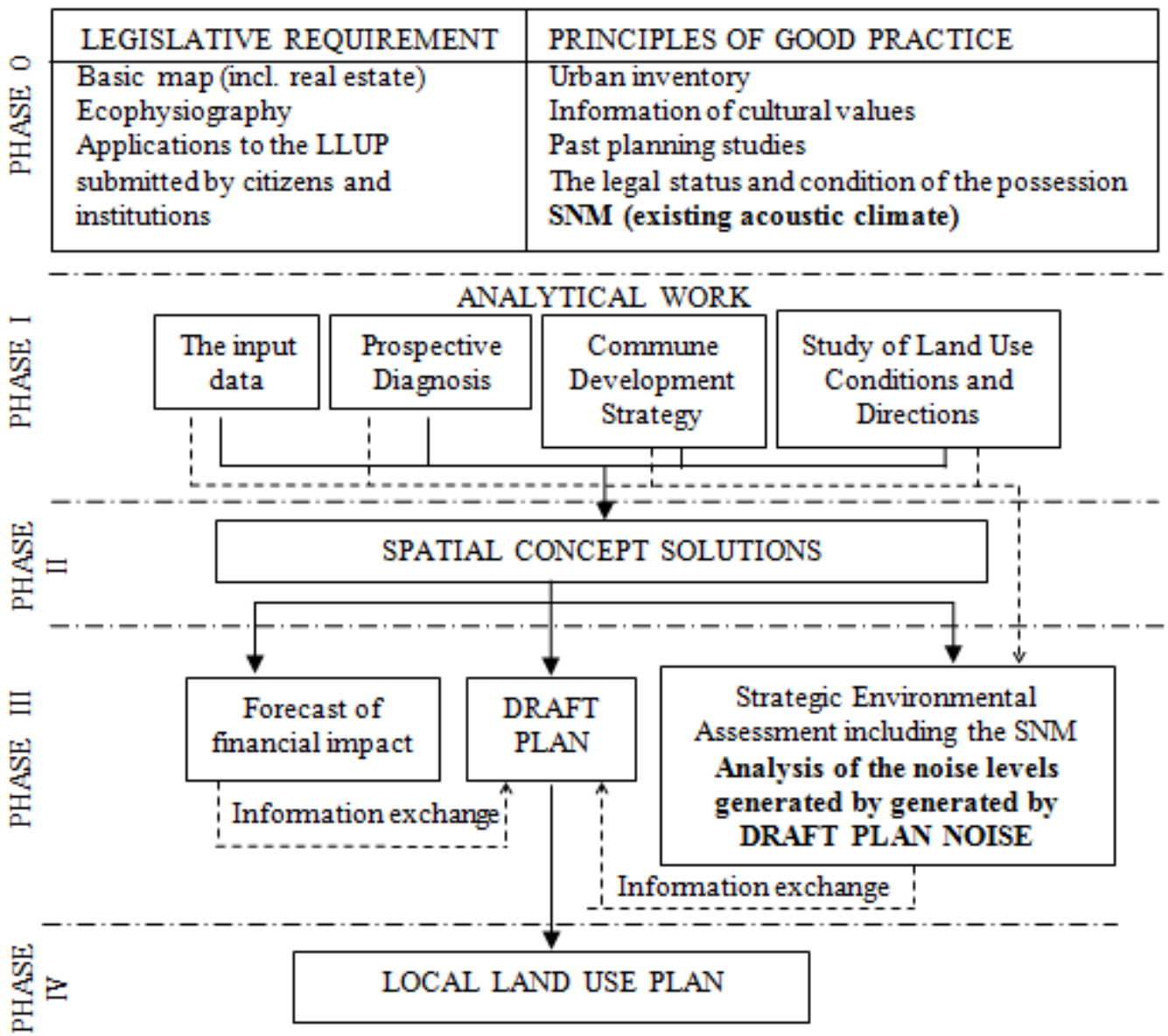

Figure 1. Stages of Local Land Use Plan including Strategic Noise Map 
This stage deals with assessing developmental conditions on the basis of available documentations as well as identifying threats to the environment and its susceptibility to changes. Phase 2 is about creation of introductory concepts of spatial development solutions, on the basis of which a draft of a plan, forecasts of financial consequences as well as the prognosis of influence of the plan solutions on natural environment (phase 3). The main aim of the prognosis is assessment of effects implementation of LLUP. On the basis of its results it is possible to verify the draft plan assumptions in terms of its negative influence on the environment. The prognosis preparation involves using initial data of the Study of Land Use Conditions and Directions, ecophysiography and cartographic documentation. After approvals, and social consultation, the project of a plan is written down in the form of a local legal act and regulations including land development and build-up parameters are formed. Phase 4 involves final works connected to introducing LLUP. Currently in Poland, the procedures of developing local plans involve an environment diagnosis in form of ecophysiography and prognosis of the impact on the environment (referred to as the prognosis). In ecophysigraphy the information concerning acoustic climate of an area originate mainly from the Study of Land Use Conditions and Directions and researches of reports concerning condition of natural environment for every voivodeship (referred to as the report). The documentation includes randomly prepared acoustic analyses. The report includes sound measurements made in major cities and does not include information on noise generated by all the groups of sources. The Study of Land Use Conditions and Directions contains only descriptive analyses of acoustic climate, excluding measured values. Analogical situation concerns the prognosis which does not include precise measurement of noise and its levels. All the analyses for existing condition and the target situation (with the fulfillment of the plan's conditions) have their source in additional documentation such as the Study of Land Use Conditions and Directions. Therefore it must be emphasized here that no precise acoustic analyses of noise levels generated by sources listed in the plan are performed._All the applied means of noise protection such as acoustic screens, location of sensitive areas and distances from noise sources do not result from precise calculation but mere interpretations of partial, hardly credible data.

The previous observations and the analysis of the previously mentioned documentation indicate the lack of complex research of environment in terms of acoustic climate for existing and forecasted conditions. Thus it has been suggested here to introduce the application of SNM in the preparation process of LLUP through the following project solutions (Fig. 1):

- SNM as a credible source of information about noise levels should be included in the initial documentation of the procedure of preparation of the Local Land Use Plan (phase 0).

- While preparing environmental forecasts, SNM analyses must be introduces since they take into account the levels of noise originating from sources indicated by the plan (phase 3).

- Once the forecast has been analysed, it has been suggested to repeat the same procedure with the draft plan and analyse it in terms of preservation the acoustic standards for noise-sensitive areas (phase 3).

When applying SNM we receive measurable noise values in decibels, which allows for clear and easily verified conclusions for the forecasts. In the same time, it prevents the commonly applied and highly incorrect methods of identifying of applying highly inaccurate expressions concerning acoustic climate such as: high, low, strong, weak for existing conditions and probably at the same level, remaining unchanged, for a target situation, with no precise values and measurement. If urban planners had taken the system of local planning including application of SNM into consideration, the problem of excess noise level would have been eliminated at the draft planning stage before its legalization. Ever since Directive 2002/49/WE concerning development of Noise Strategic Maps in agglomerations with the population of over 100,000 became effective, access to precise, unquestionable acoustic data has been considerably easier. Application of the new source of information in the process of creation of LLUP will allow for more precise estimation of boundaries of areas of different land development, especially sensitive areas, where according to the directive noise level must not exceed acceptable values. With such an approach in mind, SNM becomes a new tool supporting the process of developing urban space with the preservation of principles of sustainable development and spatial order.

\section{CONCLUSIONS}

The presentation of the problem of influence of acoustic climate on urban space planning as well as presentation of stages of the preparation of LLUP in relation to the application of a strategic noise map may lead to the following conclusions:

- The issue of environmental noise and methods of protection against it is not sufficiently identified in the process of preparation of LLUP.

- The noise map is a valuable and irreplaceable source of information about noise levels and thus should be applied by urban planners in the process of urban space planning according to principles of sustainable development and spatial order.

- Every analysis of acoustic climate of a surrounding included in a local plan are of an intuitive character and are prepared on the basis of incomplete data. It concerns both existing and target conditions after fulfillment of the plan.

- SNM enables verification of conclusions included in the forecast of environment impact concerning protection against noise since it provides measurable values of its level. Consequently It results in more precise estimation of different urban development areas and their limits, which is especially significant in terms of noise-sensitive areas where noise level requirements identified by lawmakers must be preserved.

- Applying SNM in verification of conceptual space arrangements in terms of protection against noise in the preparation of LLUP as well as their further application in the plan is a considerable advantage.

The changes affecting the space (and the accompanying noise) are of dynamic character, thus a necessity of constant monitoring emerges. Reliable information concerning alterations of environmental noise levels is crucial for the space participants in the process of proper investment decision making as well as for urban planners to be able to design an inhabitant-friendly city which complies with the rules of sustainable development. Full comprehension of the subject of the influence of environmental noise on urban space development requires further research and analyses. 


\section{REFERENCES}

Arana, M., San Martin, R., and San Martin, M.L., 2010. Strategic noise map of a major road carried out with two environmental prediction software packages. Environmental Monitoring and Assessment 163(1-40), pp. 503-513.

Asensio, C., López, J.M., Pagan, R., Pavon, L., and Ausejo, M. 2009. GPS-based speed collection method for road traffic noise mapping. Transportation Res. Part D: Transport and Environment 14(5), pp. 360-366.

Cymerman, R., 2010. Podstawy planowania przestrzennego $i$ projektowania urbanistycznego. Olsztyn, UWM.

Fyhri, A., and Aasvang, G.M., 2010. Noise, sleep and poor health: modeling the relationship between road traffic noise and cardiovascular problems. Sci Total Environ 408(21), pp. $4935-$ 4942.

Krajewska, M., and Szopińska, K., 2012. Noise Level in Relation to Real Estate Prices in Selected Settlements in Poland. FIG Working Week 2012. Knowing to manage the territory, protect the environment, evaluate the cultural heritage, Rome, Italy.

http://www.fig.net/pub/fig2012/papers/ts06h/TS06H_krajewska _szopinska_5538.pdf

Kwiecień, J., Szopińska, K., and Sztubecka, M., 2010. Problem ochrony przed hałasem na terenach zurbanizowanych na przykładzie miasta Bydgoszcz. Ekologia i Technika XVIII(4), pp. 205-212.

Souza, L.C., and Giunta, M.B., 2011. Urban indices as environmental noise indicators. Computers, Environment and Urban Systems 35(5), pp. 421-430.

Szopińska, K., 2011. Wpływ klimatu akustycznego na proces kreowania przestrzeni miejskiej. Studia $i$ Materiaty Towarzystwa Naukowego Nieruchomości 19(1), pp. 155-166.

Szopińska, K., Krajewska, M., and Bełej, M., 2012. Apartment Market Analysis Considering Environmental Noise Level in Poland. European Real Estate Society $19^{\text {th }}$ Annual Conference, Edinburgh, Scotland.

http://web.sbe.hw.ac.uk/eres2012/Book\%20of\%20Abstracts_M ain.pdf

Xie, D., Liu, Y., and Chen, J., 2011. Mapping urban environmental noise: a land use regression method. Environmental science and technology 45(17), pp. 7358-7364.

Yu, C., and Kang, J., 2011. Acoustic Sustainability in Urban Residential, 3rd International Conference on Environmental Science and Information Application Technology (ESIAT 2011), Procedia Environmental Sciences 10, pp. 471-477.

Revised March 2013 